\title{
Analisis Implementasi Wakalah dalam Akad Murabahah Pada Produk Pembiayaan Unit Mikro di PT. Bank BRI Syariah TBK. KC Bima Soetta
}

\author{
Umar Sagaf ${ }^{1^{*}}$, Guawan $^{2}$ \\ ${ }^{1,2)}$ Institut Agama Islam Muhammadiyah Bima \\ *Corresponding Author: umarsagaf72@gmail.com
}

\begin{abstract}
ABSTRAK - Penelitian ini merupakan penelitian kualitatif, teknik pengumpulan data yang digunakan adalah observasi, wawancara dan dokumentasi. Hasil penelitian menunjukan bahwa Implentasi Wakalah dalam Akad Murabahah Pada Produk Pembiayaan Unit Mikro di Bank BRI Syariah KC Bima, belum menjalankan fatwa DSN-MUI tersebut secara murni. Ketidakmurniannya terletak pada proses pengadaan barang dan penandatanganan lembar akad antara pihak bank dan nasabah. Dalam praktiknya Bank selaku penjual memberikan kebebasan pada nasabah untuk mencari sendiri barang yang diinginkan oleh nasabah, yang seharusnya pihak Bank yang menyediakan barang tersebut.
\end{abstract}

Kata Kunci - Implementasi; Wakalah; Murabahah

\begin{abstract}
This research is a qualitative research, the data collection techniques used are observation, interviews and documentation. The research results show that the Wakalah Implication in the Murabahah Contract on Micro Unit Financing Products at BRI Syariah KC Bima Bank, has not implemented the DSN-MUI fatwa purely, the impurity lies in the process of procuring goods and signing the contract sheet between the bank and the customer. as the seller, it gives freedom to the customer to find the goods desired by the customer himself, which should be the bank providing the goods.
\end{abstract}

Keywords - Implementation, Wakalah, Murabahah

\section{PENDAHULUAN}

\section{Latar Belakang Masalah}

Perbankan adalah satu lembaga yang melaksanakan tiga fungsi utama, yaitu menerima simpanan uang, meminjamkan uang, dan memberikan jasa pengiriman uang. Di dalam sejarah perekonomian kaum muslimin, pembiayaan yang dilakukan dengan akad yang sesuai syariah telah menjadi bagian dari tradisi umat Islam sejak jaman Rasulullah saw. Praktek-praktek seperti menerima titipan harta, menjaminkan uang untuk keperluan konsumsi dan untuk keperluan bisnis, serta melakukan pengiriman uang, telah berjalan sejak zaman Rasulullah. Dengan demikian, fungsi-fungsi utama perbankan modern yaitu menerima deposit, menyalurkan dana, dan melakukan transfer dana telah 
menjadi bagian yang tidak terpisahkan dari kehidupan umat Islam, bahkan sejak zaman Rasulullah saw. ${ }^{1}$

Menurut Undang-Undang No. 7 Tahun 1992 jo. Undang-Undang No. 10 Tahun 1998 tentang Perbankan dan Undang-Undang No. 23 Tahun 1999 jo. Undang-Undang No. 3 Tahun 2004 tentang Bank Indonesia, bahwa lembaga perbankan memiliki fungsi sebagai penghimpun dana dari masyarakat dan menyalurkan kembali dana tersebut kepada masyarakat melalui kredit usaha. ${ }^{2}$

Dari observasi yang penulis lakukan di Bank BRI Syariah KC Bima, bank tersebut menghadirkan produk pembiayaan Murabahah bil Wakalah pada unit mikro dengan tujuan investasi dan membantu usaha produktif dalam mengembangkan usaha nasabah. Pembiayaan unit mikro merupakan pembiayaan yang dibatasi jumlah platfon pembiayaan yang diberikan kepada nasabah dengan jangka waktu yang dibatasi oleh pihak bank.

Berdasarkan latar di atas, penelitian ini berfokus pada bagaimana implementasi wakalah dalam akad murabahah pada produk pembiayaan Unit Mikro pada Bank BRI Syariah KC Bima SOETTA dan apakah implementasi wakalah dalam akad murabahah pada Unit Mikro di Bank BRI Syariah KC Bima SOETTA sudah sesuai dengan akad syariah.

\section{LANDASAN TEORI}

Akad Wakala

Pengertian Wakalah

Wakalah secara etimologis adalah penjagaan, jaminan, tanggungan, pemberian kuasa. Dan juga bisa diartikan pelimpahan kekuasaan oleh seseorang sebagai pihak pertama kepada orang lain sebagai pihak kedua dan hanya melaksanakan sesuatu sebatas wewenang yang diberikan oleh pihak pertama, namun apabila wewenang yang diberikan oleh pihak pertama kepada pihak kedua telah dilaksanakan oleh pihak kedua sesuai dengan perintah yang diberikan pihak pertama, maka semua resiko dan tanggung jawab tersebut sepenuhnya ditanggung pihak pertama ${ }^{3}$.

\section{Landasan Hukum}

1. Di dalam Al-Quran

\footnotetext{
${ }^{1}$ Abdul Muhith, "Sejarah Perbankan Syariah”, Jurnal Kajian KeIslaman dan Pendidikan, Vol. 01, No. 2 (September, 2012), h.72.

${ }^{2}$ Bagya Agung Prabowo, "Konsep Akad Murabahah Pada Perbankan Syariah (Analisa Kritis Terhadap Aplikasi Konsep Akad Murabahah Di Indonesia Dan Malaysia)," Jurnal Hukum, Vol. 16, No. 1 (Januari, 2009), h.106-107.

${ }^{3}$ Muhammad Syafi'i Antonio, “Bank Syariah dari Teori ke Praktik”, (Jakarta : Gema Insani Press, 2001), h.75.
} 


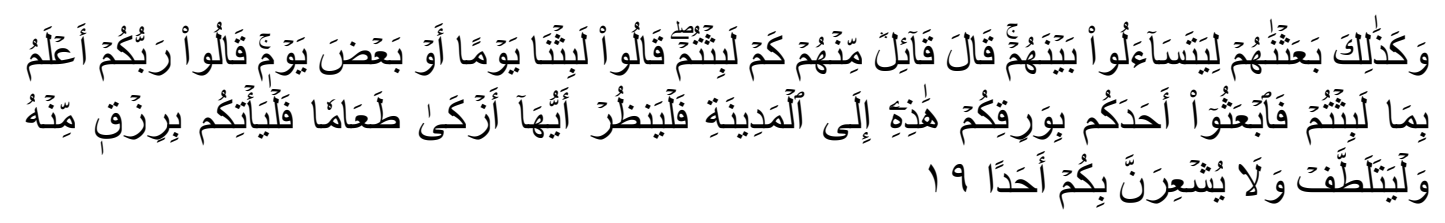

Terjemahanya: Dan demikianlah Kami bangunkan mereka agar mereka saling bertanya di antara mereka sendiri. Berkatalah salah seorang di antara mereka: Sudah berapa lamakah kamu berada (disini?)." Mereka menjawab: "Kita berada (disini) sehari atau setengah hari." Berkata (yang lain lagi): "Tuhan kamu lebih mengetahui berapa lamanya kamu berada (di sini). Maka suruhlah salah seorang di antara kamu untuk pergi ke kota dengan membawa uang perakmu ini, dan hendaklah dia lihat manakah makanan yang lebih baik, maka hendaklah ia membawa makanan itu untukmu, dan hendaklah ia berlaku lemah-lembut dan janganlah sekali-kali menceritakan halmu kepada seorangpun. (QS. Al-Kahfi: 19). ${ }^{4}$

2. Ijma'

Beberapa ulama berijma' bahwa wakalah itu dibolehkan dalam Islam. Menurut Ibnu Qodamah, wakalah itu boleh dilakukan, baik dengan imbalan maupun tanpa imbalan.

3. Hadits

Hadits Rasulullah dalam kitab Al-Muwathatha

"Bahwasanya Rasulullah saw. mewakilkan kepada Abu Rafi' dan seorang anshar untuk mewakilkannya mengawini Maimunah binti Harits.

4. Rukun dan Syarat Wakalah

Menurut kelompok Hanafiah, rukun wakalah itu hanya ijab qabul, akan tetapi jumhur ulama tidak memiliki pendapat yang serupa, mereka berpendirian bahwa rukun dan syarat wakalah sekurang-kurangnya terdapat empat rukun yaitu pihak pemberi kuasa (muwakkil), pihak penerima kuasa (wakil), obyek yang dikuasakan (tawkil) dan ijab qabul (sigat). Keempatnya dijelaskan sebagai berikut: ${ }^{5}$

a. Orang yang mewakilkan (al-muwakkil)

b. Orang yang di wakilkan (al-wakil)

c. Objek yang di wakilkan

d. Sighat / Ijab qabul

e. Berakhirnya kontrak wakalah

5. Macam-macam wakalah

${ }^{4}$ QS. Al-Kahfi: 19

${ }^{5}$ Hendi Suhendi, Fiqih Muamalah (Jakarta: Grafindo Persada, 2010), h.234 -235. 
a. Wakalah al-khassah adalah wakalah dimana pemberi wewenang untuk menggantikan sebuah posisi pekerjaan yang bersifat spesifik.

b. Al-wakalah al-ammah adalah akad wakalah dimana pemberian wewenang bersifat umum, tanpa adanya penjelasan yang rinci.

\section{Akad Murabahah}

\section{Pengertian Murabahah}

Definisi lain murabahah adalah akad jual beli atas barang tertentu, dimana penjual menyebutkan harga pembelian barang kepada pembeli kemudian menjual kepada pihak pembeli dengan mensyaratkan keuntungan yang di harapkan sesuai dengan jumlah tertentu. ${ }^{6}$

\section{Dasar Hukum Murabahah}

1. Di dalam Al-Qur'an

Surah An-Nisa Ayat 29

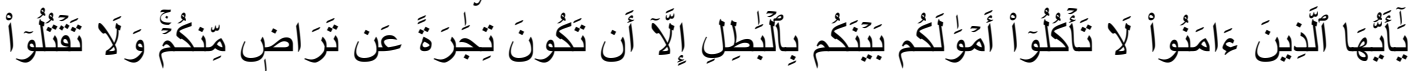

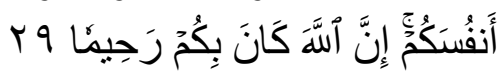

Terjemahanya: Hai orang-orang yang beriman, janganlah kamu saling memakan harta sesamamu dengan jalan yang batil, kecuali dengan jalan perniagaan yang berlaku dengan suka sama-suka di antara kamu. Dan janganlah kamu membunuh dirimu; sesungguhnya Allah adalah Maha Penyayang kepadamu. ${ }^{7}$

2. Murabahah Berdasarkan Hukum Positif

Murabahah merupakan suatu produk atau skim yang paling popular dalam pratek pembiayaan pada perbankan syariah.

3. Murabahah Berdasarkan Fatwa Nomor 04/DSN/MUI/IV/2000 Jo Kompilasi Hukum Ekonomi Syariah.

Berkenaan dengan pembiayaan murabahah dalam kegiatan perbankan syariah, DSN telah mengeluarkan fatwa nomor 04/DSN-MU/IV/2000 tentang murabahah yang menetapkan pedoman bagi bank syariah yang memiliki fasilitas murabahah dan ditegaskan kembali dalam Kompilasi Hukum Ekonomi Syariah.

4. Rukun dan syarat murabahah

a. Rukun Murabahah bil Wakalah

Dalam rukun murabahah bil wakalah sama dengan akad murabahah, namun perbedaan dalam akad ini terdapat pada pembelian barang.

a) Penjual (bai')

b) Pembeli (musytary)

c) Barang yang dibeli.

${ }^{6}$ Ismail, Perbankan Syariah, (Jakarta: PT. Kharisma Putra Utama, 2017), h.138.

${ }^{7}$ QS. An-Nisa:29. 
d) Harga barang.

e) Muwakil atau pemberi kuasa adalah pihak yang memberikan kuasa kepada pihak lain.

f) Taukil atau objek akad.

g) Shigat atau ijab dan qabul.

b. Syarat Murabahah bil Wakalah

a) Barang yang yang diperjual belikan harus halal dan bebas dari najis.

b) Penjual memberitahu modal yang akan diberikan kepada nasabah.

c) Kontrak pertama harus sah sesuai dengan rukun yang telah ditetapkan.

d) Kontrak harus bebas dari riba.

e) Penjual harus memberitahu atau menjelaskan bila terjadi cacat atas barang sesudah pembelian.

f) Penjual harus menyampaikan semua hal yang diberkaitan dengan pembelian, misalnya jika pembelian tersebut dilakukan secara utang.

g) Objek barang yang akan dibeli harus jelas dan diwakilkan kepada nasabah yang mengajukan pembiayaan dengan akad murabahah bil wakalah.

h) Tidak bertentangan dengan syariat Islam. ${ }^{8}$

\section{Produk Pembiayaan Unit Mikro}

\section{Pengertian Pembiayaan}

Pembiayaan merupakan suatu fasilitas keuangan yang memungkinkan seseorang atau badan usaha untuk meminjam uang untuk membeli produk dan membayarnya kembali dalam jangka waktu yang ditentukan. Menurut undang undang No. 10 tahun 1998.

\section{Pembiayaan Usaha Mikro}

Usaha mikro adalah usaha prodiktif milik perorangan dan/atau badan usaha perorangan yang memiliki kekayaan bersih (tidak termasuk tanah dan bangunan) paling banyak Rp. 50.000.000,00 (lima puluh juta rupiah) dan hasil penjualan tahunan paling banyak Rp. 300.000.000,00 (tiga ratus juta rupiah).

\section{METODOLOGI PENELITIAN}

\section{Jenis Penelitian}

Penelitian ini termasuk jenis penelitian lapangan (Field Research) dengan mengunakan pendekatan kualitatif, yaitu prosedur penelitan yang

\footnotetext{
${ }^{8}$ Ascarya, Akad dan Produk Bank Syariah, (Jakarta: PT Raja Grafindo Persada, 2008), h.104
} 
menghasilkan data diskriptif berupa kata-kata tertulis atau lisan dari perilaku orang-orang yang dapat diamati. Jadi penelitian ini adalah penelitian yang menghasilkan prosedur analisis yang tidak menggunakan prosedur analisis statistik atau cara kuantifikasi lainnya. Penelitian kualitatif adalah sebuah penelitian yang tidak menggunakan angka-angka yang bersifat alamiah yang di dapat dari data-data yang diperoleh dan tidak menggunakan alat statistic untuk mengelola data. ${ }^{9}$

\section{Jenis Data Dan Sumber Data}

\section{Data Primer}

Data primer merupakan data yang diperoleh secara langsung dari sumber asli yang diperoleh langsung dari hasil wawancara dan observasi dengan objek penelitian yaitu pihak Bank BRI Syariah SOETTA. KC Bima.

\section{Data Sekunder}

Data sekunder merupakan data yang diperoleh oleh suatu orgnisasi atau perorangan dalam bentuk yang sudah jadi berupa publikasi, data yang diperoleh dari buku-buku, jurnal, internet, serta sumber lainya yang dapat dijadikan bahan penunjang penulisan Skripsi ini.

\section{Metode Pengumpulan Data}

\section{Wawancara}

Wawancara digunakan apabila peneliti ingin melakukan studi pendahuluan untuk menemukan permasalahan yang harus diteliti, dan juga apabila peneliti ingin mengetahui hal-hal dari responden yang lebih mendalam dan jumlah respondennya sedikit/kecilin ${ }^{10}$.

\section{Observasi}

Observasi dalah suatu kegiatan mendapatkan informasi yang diperlukan untuk menyajikan gambaran riil suatu peristiwa atau kejadian untuk menjawab pertanyaan penelitian.

\section{Dokumentasi}

Dokumentasi merupakan catatan peristiwa yang sudah berlalu. Dokumen bisa berbentuk tulisan gambaran atau karya karya monumental dari seseorang.

\section{Teknis analisis data}

Teknik analisis data menurut Miles dan Huberman terdiri dari tiga tahapan yang harus dikerjakan dalam menganalisis data penelitian kualitatif, yaitu reduksi data (data reduction), paparan data (data display), dan penarikan kesimpulan (conclusion drawing/verification).

${ }^{10}$ Sugiono, Metode Penelitian Kuantitatif, Kualitatif, dan $R \& D$, (Bandung: Alfabeta, 2016), h. 137
}

${ }^{9}$ Lexy J. Moleong, Metode Penelitian Kualitatif, (Bandung : PT. Remaja Rosdakarya, 


\section{HASIL PENELITIAN}

\section{Implementasi Wakalah dalam Akad Murabahah pada Produk Pembiayaan Unit Mikro pada Bank BRI Syariah KC Bima.}

Berdasarkan hasil Wawancara dengan ibu Emi sebagai Nasabah Bank BRI Syariah KC Bima mengatakan bahwa:

"Setelah saya melalui proses pengajuan pembiayaan, dengan memberikan kelengkapan identitas saya dan melakukan pengisi formulir pengajuan pembiayaan. Saya tidak menerima barang yang saya minta, melainkan saya diberi kuasa oleh pihak bank untuk membeli dan mencari barang yang saya butuhkan yang sesuai dengan apa yang saya cantumkan pada formulir pembiayaan setelah itu saya memberikan kepada pihak bank kwitansi dari pembelian barang saya" ${ }^{11}$

Selanjutnya Wawancara dengan Bapak Iwan Ardiansyah Selaku UH (Unit Head) mengungkapkan bahwa:

“Karena kami selaku pihak bank tidak mampu menyediakan barang, maka pembiayaan unit mikro ini menggunakan akad murabahah bil wakalah, karena keterbatasan kami. Mengingat, fatwa DSN-MUI mengharuskan ada keterwakilan dalam pembelian barang, dan itu harus diikat dengan akad wakalah" ${ }^{12}$

Selanjutnya dalam wawancara dengan Bapak Fajrin Selaku Financing Support SPV menyatakan bahwa:

"Dalam proses penandatanganan akad murabahah dengan nasabah, hal yang ditekankan pertama adalah tentang prinsip jual beli (akad murabahah), sehingga yang dijelaskan kepada nasabah adalah nominal pembiayaan adalah harga beli atau harga pokok, kemudian keuntungan yang diambil oleh bank dalam jual beli tersebut adalah margin atau akumulasi antara harga beli atau harga pokok dan margin adalah harga jual". 13

Implementasi Wakalah dalam Akad Murabahah Pada Produk Pembiayaan Unit mikro pada bank BRI Syariah Bima

Berdasarkan hasil wawancara dengan Bapak Iwan Ardiansyah mengungkapkan bahwa:

\footnotetext{
${ }^{11}$ Ibu Emi, Wawancara, Kediamannya, 11 Desember 2020

${ }^{12}$ Iwan Ardiansyah, Wawancara, Bank BRI Syariah KC Bima, 30 November 2020

${ }^{13}$ Fajrin, Wawancara, Bank BRI Syariah KC Bima, 30 November 2020
} 
“Dalam fatwa DSN-MUI No.04/DSN-MUI/IV/2000 tentang murabahah menyatakan "bank membeli barang yang diperlukan atas nama bank sendiri dan pembelian ini harus sah dan bebas dari riba. Namun dalam praktiknya bank selaku penjual memberikan kebebasan kepada nasabah untuk mencari sendiri barang yang diinginkannya, karena selain melakukan perjanjian jual beli (akad murabahah) sebelumnya dilakukan juga akad wakalah (mewakilkan) dalam hal ini bank memberikan kuasa kepada pihak nasabah uuntuk mencari barang yang diinginkan sesuai yang tertera dalam RAB perjanjian murabahah dan hal tersebut harus dikawal dan dikontrol oleh pihak bank sampai benar-benar pihak nasabah membelanjakan barang tersebut sesuai RAB agar prinsip syariah berjalan dengan benar". ${ }^{14}$

Sedangakan waawancara dengan Bapak Ilham Selaku Mikro Marketing Manager menyatakan bahwa:

"Pada dasarnya barang yang tertuang dalam RAB ketika akad murabahah adalah milik bank sejumlah nominal pembiayaan yang diajukan oleh nasabah atau disebut harga pokok, kemudian dilakukan proses perjanjian jual beli (akad murabahah) barang yang tertuang dalam RAB tersebut dijual ke nasabah dengan harga lebih atau disebut dengan harga jual, namun sebelum akad murabahah terlebih dahulu dilakukan akad wakalah untuk mewakilkan atau mengusakan pembelian barang dalam RAB tersebut dilakukan oleh nasabah. Nasabah menuliskan barang yang akan dibeli dalam RAB sejumlah harga beli atau harga pokok pembiayaan dan itu yang akan menjadi obyek akad murabahah, namun setelahnya nasabah tersebut harus wajib membelanjkan dan pembiayaan tersebut sesuai dengan RAB yang dituliskan dan hal tersebut tetap dikawal dan dikontrol oleh pihak bank untuk memastikan proses akad murabahah benarbenar dijalankan dengan baik" ${ }^{15}$

\section{PEMBAHASAN HASIL PENELITIAN}

Implementasi Wakalah dalam akad Murabahah pada Produk Pembiayaan Unit Mikro pada Bank BRI Syariah KC Bima

Sebagaimana penulis analisis di Bank BRI Syariah KC Bima untuk melihat bagaiman praktik wakalah dalam akad murabahah pada pembiayaan Unit Mikro

\footnotetext{
${ }^{14}$ Iwan Ardiansyah, Wawancara, Bank BRI Syariah KC Bima, 30 November 2020

${ }^{15}$ Ilham, Wawancara, Bank BRI Syariah KC Bima, 30 November 2020
} 
di Bank BRI Syariah KC Bima, bahwa proses Wakalah dalam Akad Murabahah pada Bank BRI Syariah KC Bima telah memenuhi ketentuan yang berlaku.

Pembiayaan pada Unit Mikro di Bank BRI Syariah KC Bima telah memenuhi unsur-unsur yang disyariatkan dalam proses jual beli. Mengingat pada unsur murabahah tersebut telah terpenuhi, yaitu terdapat penjual, barang yang diperjualbelikan, akad dan pembeli.

Setelah nasabah yang berposisi sebagai wakil dari Bank dalam pembelian barang dan atas nama bank, maka dengan demikian akad wakalah gugur dengan ditandainya pelaporan pembelian barang yang diberikan nasabah kepada pihak bank. Baru kemudian akad murabahah dapat dilakukan antara pihak bank sebagai secara prinsip pemilik barang dan nasabah sebagai pembeli.

\section{Analisis Implementasi Wakalah dalam Akad Murabahah pada Unit Mikro di Bank BRI Syariah SOETTA. KC Bima}

Berdasarkan ayat Al-Qur'an surat Al-Baqarah ayat 275, Allah mengatakan bahwa setiap transaksi murabahah atau jual beli harus bebas dari riba, termasuk pula barang yang diperjualbelikan dalam murabahah pun juga harus barang yang halal. Selain ayat Al-Qur'an diatas syarat mengenai barang yang diperjualbelikan juga dapat dilihat dari ketentuan berdasarkan Fatwa DSN-MUI No.04/DSN-MUI/IV/2000 yang berbunyi barang yang diperjualbelikan bukan termasuk barang yang diharamkan.

Akad murabahah adalah akad transaksi penjualan barang dengan menyatakan harga perolehan dan keuntungan margin disepakati oleh penjual dan pembeli, dengan pembayaran atas akad murabahah dapat dilakukan secara tangguh dan tunai.

Akad Murabahah dikatakan sah hanya ketika biaya-biaya perolehan barang dapat ditentukan secara pasti. Jika biaya-biaya tidak dapat dipastikan, barang atau komoditas tersebut tidak dapat dijual dengan prinsip akad murabahah.

\section{PENUTUP}

Berdasarkan hasil penelitian yang telah dilakukan, maka dikemukakan beberapa kesimpulan terkait dengan Analisis Implementasi Wakalah dalam Akad Murabahah Pada Produk Pembiayaan Unit Mikro pada Bank BRI Syariah KC Bima diantaranya:

1. Implementasi Wakalah dalam Akad Murabahah pada Produk Pembiayaan Unit Mikro pada Bank BRI Syariah KC Bima SOETTA: pihak Bank BRI Syariah KC Bima belum menjalankan fatwa tersebut secara murni. 
Ketidakmurniannya terletak pada proses pengadaan barang dan penandatangan lembar akad antara pihak bank dan nasabah

2. Implementasi wakalah dalam akad murabahah pada Unit Mikro di Bank BRI Syariah KC Bima SOETTA: Dalam praktiknya Bank selaku penjual memberikan kebebasan pada nasabah untuk mencari sendiri barang yang diinginkan oleh nasabah, yang seharusnya pihak Bank yang menyediakan barang tersebut

\section{DAFTRA PUSTAKA}

Abdul Muhith, "Sejarah Perbankan Syariah", Jurnal Kajian KeIslaman dan Pendidikan, Vol. 01, No. 2 September, 2012.

Adiwarman Karim, Bank Islam: Analisis Fiqih dan Keuangan, Jakarta: IIIT Indonesia, 2003.

Arinda Firdianti, “Implementasi Manajemen Berbasis Sekolah dalam Meningkatkan Presentasi belajar Siswa", Yogyakarta: CV. Gre Publishing, 2018.

Bagya Agung Prabowo, "Konsep Akad Murabahah Pada Perbankan Syariah (Analisa Kritis Terhadap Aplikasi Konsep Akad Murabahah Di Indonesia Dan Malaysia)," Jurnal Hukum, Vol. 16, No. 1 Januari, 2009.

Djoko Muljono, Perbankan dan Lembaga Keuangan Syariah, Yogyakarta: Andi Offset, 2015

Eka Dewi Sulistianingrum, "Implementasi Murabahah Bil Wakalah", ("Skripsi”, Institut Agama Islam Negari (IAIN) Metro, 2018.

Helmi Karim, M.A. Fiqh Muamalah Jakarta: PT. Raja Grafindo Persada, cet. I, 1993. https:/ / databoks.katadata.co,id/datapublish/2019/09/24/berapa-jumlah-

penduduk-muslim-indonesia.

Hendi Suhendi, Fiqih Muamalah Jakarta: Grafindo Persada, 2010.

Haryo Normala Meilano, Burhanudin Harhap, "Implementasi Akad Wakalah dalam

Pembiayaan Murbahah pada Bank Negara Indonesia (BNI) syariah Cabang Surakarta", Masalah Hukum, Jilid 47 No. 2, April 2018

Isnawati Nais Dan Hasanudin, "Fiqih Muamalah Dan Aplikasinya Pada Lembaga Keuangan Syariah" Jakarta: Lembaga Penelitian UIN Jakarta, 2011.

Ismail, Perbankan Syariah, (Jakarta: PT. Kharisma Putra Utama, 2017), 138.

J. R. Raco, Metode Penelitian Kualitatif Jenis, Karakteristik, dan keunggulannya, Jakarta: PT Gramedia, 2010 
L. Hakim, A. Anwar, "Pembiayaan Murabahah Pada Perbankan Syariah Dalam Perspektif Hukum Di Indonesia", Al-Urban: Jurnal Ekonomi Syariah dan Filantropi Islam, No. 2, Vol. 1 Desember, 2017.

Lexy J. Moleong, Metode Penelitian Kualitatif, (Bandung : PT. Remaja Rosdakarya, 2005). 125.

Manfarisah Zulfiyanda, Faisal, “Akad Pembiayaan Murabahah Bil Wakalah Pada Pt. Bank Rakyat Indonesia Syariah Lhokseumawe”, Suloh Jurnal Program Studi Magister Hukum, Vol. 8, No. 1 April, 2020.

Muhamad Turmudi, "Pembiayaan mikro BRI Syariah: Upaya pemberdayaan dan peningkatan UMKM oleh BRI Syariah ımang Kendari." Li Falah: Jurnal Studi Ekonomi dan Bisnis Islam, Vol. 2. No. 22017.

Muhammad Syafi'i Antonio, “Bank Syariah dari Teori ke Praktik”, Jakarta : Gema Insani Press, 2001.

Mia Tri Oktavia, "Peranan Akad Akad Murabahah Pada Pembiayaan Mikro di BRI Syariah KCP Bintaro", ("Skripsi", Universitas Muhammadiyah Jakarta, 2018.

Nofinawati, "Akad Dan Produk Perbankan Syariah", Fitrah, No. 2, Vol. 8 JuliDesember, 2014.

Putri Indah Sari Daulay, "Pengaruh Pendapatan Bagi Hasil Pembiayaan Mudharabah Dan Pembiayaan Musyarakah Terhadap Return On Equity (ROE) Pada Pt. Bank Syariah Mandiri, Tbk", "Skripsi”, Universitas Islam Negeri Sumatera Utara Medan, 2019.

Rika Fitranti, "Manajemen Risiko Pembiayaan Mikro Pada BRI Syariah Kantor Cabang Pembantu Cipulir", "Skripsi", Universitas Islam Negeri Syarif Hidayatullah Jakarta, 2014.

Rachmadi Usman, Produk dan Akad Perbankan Syariah di Indonesia, Bandung: PT. Citra Aditya Bakti. 2009.

Siti Yunitarini, "Prospek Dan Kendala Bank Syariah Di Era Globalisasi”, Jurnal Ekonomi dan Bisnis, Vol. 5, No. 2 September, 2007.

Setia Budhi Wilardjo, "Pengertian dan Perkembangan Bank Syari'ah Di Indonesia", Value Added, Vol 2, No. 1 September, 2004-2005.

Sunardi, Fety Aniarsih, "Faktor-Faktor Yang Memengaruhi Minat Masyarakat Muslim Menabung Di Bank Syariah" Jurnal Ekonomi dan Perbankan Syariah, 53-54.

Sugiono, Metode Penelitian Kuantitatif, Kualitatif, dan RED, (Bandung: Alfabeta, 2016.

Suharsimi Arikunto, Prosedur Penelitian Suatu Pendekatan Praktik., Jakarta: Rineka Cipta, 2006. 
Sholihatin Khofsah,"Implementasi Pembiayaan Murabahah Bil Wakalah Sebagai Upaya Untuk Meningkatkan Ekonomi Peternak Sapi di BMT Al-Hijrah Kan Jambung", ("Skripsi”, Universitas Islam Negari Maulana Malik Ibrahim Malan, 2017.

Tri Setiady, "Pembiayaan Murabahah Dalam Perspektif Fiqih Islam, Hukum Positif Dan Hukum Syariah", Fiat Justisia Jurnal Ilmu Hukum, Vol. 8, Nol. 3, juli-september 2014.

Yadi Janwari, Lembaga Keuangan Syariah, Bandung: PT Remaja Rosdakarya Offset, 2015.

Zulfiyanda,Faisal,Manfarisah, "Akad Pem aan Muabahah Bil Wakalah Pada PT. Bank Rakyat Indonesia Syariah", Jurnal Program Studi Magister Hukum, Vol. 8, No. 1 (April 2020) 